\title{
PRODUKTIVITAS PENEBANGAN PADA HUTAN JATI (Tectona Grandis) RAKYAT DI KABUPATEN BONE
}

\author{
Felling Productivity on Community Teak (Tectona grandis) Forest Bone Regency \\ Andi Mujetahid
}

\begin{abstract}
Community teak forest in Bone Regency was $\pm 4,220$ ha in wide, spreading in Amali, Ulaweng, Bengo, Mare, Tonra, Kahu, Salomekko, Ajangale, Dua Boccoe, Lamuru, Tellulimpoe, Lappariaja, Libureng, Palakka, Bontocani and Ponre Subdistricts. The descriptive method was used to describe and clarify felling activities of community teak forest. The quantitative approach was conducted by recording and analyzing the data such as working time, length, diameter, volume, , productivity, etc. Time measurement of each work element with non stop method to get total time. The study was aimed to felling productivity with chainsaw $5,12 \mathrm{~m}^{3} /$ day.
\end{abstract}

Key words: community teak forest, felling, working time, productivity

\section{PENDAHULUAN}

Produktivitas kerja penebangan merupakan salah satu informasi dasar yang penting terutama untuk kegiatan perencanaan, pengawasan dan evaluasi. Proses pengawasan dan evaluasi meliputi beberapa kegiatan antara lain penentuan standar yang akan digunakan untuk penelitian, pengukuran pekerjaan, membandingkan hasil pekerjaan dengan standar yang dipakai serta mengambil tindakan perbaikan jika diketahui adanya penyimpangan. Selain berfungsi untuk kegiatan perencanaan, pengawasan dan evaluasi pekerjaan, produktivitas kerja juga berfungsi untuk penentuan atau perhitungan upah. Analisis produktivitas kerja ini bertujuan untuk mengetahui produktivitas kerja dengan cara menghitung waktu yang digunakan pada setiap elemen kerja, sehingga diperoleh waktu total dan dibandingkan dengan keluaran berupa volume kayu yang ditebang atau disarad pada pengusahaan hutan skala kecil yang diusahakan oleh masyarakat.

Dalam usaha untuk menemukan standar produktivitas kerja dari suatu pekerjaan yang akan dimanfaatkan untuk kepentingan evaluasi usaha dan penilaian produktivitas tenaga kerja, perlu dimulai dengan analisis yang dilaksanakan secara mendalam. Metode yang digunakan untuk penentuan produktivitas kerja adalah time study. Time study merupakan salah satu metode yang paling banyak diterapkan dalam pengukuran kerja. Metode tersebut dipergunakan secara luas di seluruh dunia dalam berbagai tipe kegiatan produksi untuk penentuan input waktu dalam proses produksi.

Hasil time study dimanfaatkan untuk penentuan tarif upah yang adil dan selain untuk kepentingan tersebut, pemanfaatan yang lebih penting adalah rasionalisasi produksi. Apabila data time study tersebut digunakan untuk rasionalisasi produksi, penggunaan tersebut akan terkait dengan salah satu atau beberapa tujuan sebagai berikut: peningkatan organisasi dan perencanaan kerja, pengawasan dan pengambilan tindak lanjut, peningkatan dan perbandingan metoda kerja, peralatan atau mesin-mesin serta untuk penyusunan data kinerja dan perhitungan biaya.

Yang dimaksud dengan produktivitas kerja adalah hasil kerja dalam satuan tertentu (luas atau volume, dII) dari seorang pekerja atau satu regu kerja selama sehari (HOK atau HRK) untuk selama tujuh jam kerja. Untuk analisis produktivitas digunakan pendekatan pengukuran waktu kerja (time study). Langkah-langkah dalam penentuan produktivitas antara lain pengamatan waktu kerja, pengukuran hasil kerja dan perhitungan produktivitas kerja.

\section{BAHAN DAN METODE}

\section{Metode pengumpulan data}

Metode yang digunakan adalah metode deskriptif yang bertujuan untuk mendeskripsikan 
dan menjelaskan kegiatan penebangan hutan rakyat. Pendekatannya secara kuantitaf yaitu pendekatan yang dilakukan dengan pencatatan dan analisis data hasil penelitian seperti waktu kerja pada setiap elemen kerja, panjang dan diameter batang, volume, produktivitas, dan lainlain.

Produktivitas kerja dihitung berdasarkan pengukuran waktu kerja (time study). Elemen kerja adalah bagian dari waktu kerja yang dilaksanakan secara berurutan dalam suatu siklus kerja yang meliputi persiapan, menentukan arah rebah, membuat takik rebah, membuat takik balas, pemotongan cabang dan ranting, pembagian batang.

Pengukuran waktu kerja menggunakan metode non stop, yaitu stopwatch terus dijalankan sejak awal kegiatan sampai berakhir. Pada stiap awal dan akhir setiap elemen kerja dicatat waktu yang ditunjukkan oleh stopwatch. Waktu kerja setiap elemen kerja diperoleh dari selisih penunjukan waktu antara elemen kerja yang bersangkutan dengan elemen kerja sebelumnya.

Pemilihan metode non stop didasarkan pada alasan lebih mudah dan praktis dalam pelaksanaannya karena elemen kerja penebangan dan penyaradan berlangsung secara berkesinambungan atau tidak ada sela berhenti di antara elemen kerja.

\section{Metode analisis data}

Produktivitas kerja penebangan dan penyaradan merupakan produktivitas rata-rata dari suatu siklus kegiatan yang dihitung berdasarkan hasil pengukuran waktu kerja yang telah diolah ke dalam bentuk tabulasi dengan rumus:

Ptp $=\mathrm{Va} / \mathrm{WTp}$

di mana:

Ptp $=$ Produktivitas penebangan $\left(\mathrm{m}^{3} / \mathrm{jam}\right)$

$\mathrm{Va}=$ Volume batang aktual $\left(\mathrm{m}^{3}\right)$

Wtp = Waktu kerja kegiatan penebangan (jam)

\section{HASIL DAN PEMBAHASAN}

Penebangan kayu merupakan kegiatan merebahkan pohon yang kemudian memotong menjadi bagian batang yang layak sarad. Penebangan merupakan langkah awal untuk pemanfaatan kayu secara komersial. Efisiensi dan efektifitas teknik pada kegiatan penebangan menentukan efisiensi pemanfaatan kayu secara keseluruhan.

Produktivitas kerja penebangan adalah perhitungan waktu efektif dimulainya saat operator chainsaw melakukan persiapan, menentukan arah rebah, membuat takik rebah, takik balas, membersihkan, cabang, dahan dan ranting, membagi batang, dan pembuatan sortimen.

\section{Sebaran waktu kerja}

Langkah awal dalam perhitungan dan penentuan produktivitas kerja penebangan dimulai dari pengamatan waktu kerja pada setiap elemen kerja. Elemen kerja adalah bagian dari suatu siklus kerja secara berurutan yang dapat dihitung atau diukur waktunya.

Pengukuran waktu kerja bertujuan untuk mengetahui penggunaan waktu pada setiap elemen kerja, sehingga dapat diketahui waktu kerja yang berlebih dan dapat dikurangi atau penggunaan waktu yang sedikit dapat ditambahkan. Dengan demikian penggunaan waktu tersebut sesuai dengan elemen kerja yang bersangkutan. Waktu kerja penebangan disajikan pada Tabel 1.

\section{Waktu persiapan}

Waktu persiapan adalah waktu yang digunakan untuk mempersiapkan kelancaran pelaksanaan kegiatan penebangan seperti pemeriksaan dan penambahan bahan bakar minyak, oli pelumas rantai, mengencangkan dan menggiwar rantai, membersihkan atau menghilangkan rintangan di sekitar (akar-akar di seputar batang, semak-semak) dan lain sebagainya. Rata-rata waktu yang digunakan untuk elemen kerja persiapan pada setiap lokasi berkisar antara 0,38-3,08 menit dengan rata-rata keseluruhan sebesar 1,25 menit.

\section{Waktu penentuan arah rebah}

Waktu penentuan arah rebah adalah waktu yang digunakan untuk menentukan arah rebahnya pohon. Rata-rata waktu yang digunakan untuk elemen kerja penentuan arah rebah pada setiap lokasi berkisar antara 0,47-3,87 menit dengan rata-rata keseluruhan sebesar 1,65 menit. Waktu tersebut bervariasi antara satu pohon dengan 
Tabel 1. Felling Working Time on Community Teak Forest Bone Regency

\begin{tabular}{|c|c|c|c|c|c|c|c|c|c|}
\hline \multirow[b]{2}{*}{ No. } & \multirow[b]{2}{*}{$\begin{array}{c}\text { Lokasi/ } \\
\text { Desa }\end{array}$} & \multirow[b]{2}{*}{$\begin{array}{c}\mathrm{L} \\
(\mathrm{m})\end{array}$} & \multirow[b]{2}{*}{$\begin{array}{c}d \\
(\mathrm{~cm})\end{array}$} & \multicolumn{6}{|c|}{ Waktu Kerja (menit) } \\
\hline & & & & Persiapan & $\begin{array}{l}\text { Penentuan } \\
\text { arah rebah }\end{array}$ & $\begin{array}{l}\text { Takik } \\
\text { rebah }\end{array}$ & $\begin{array}{l}\text { Takik } \\
\text { balas }\end{array}$ & $\begin{array}{c}\text { Pembagian } \\
\text { batang }\end{array}$ & Total \\
\hline 1. & Bila 1 & 6,75 & 22,52 & 0,65 & 0,47 & 3,09 & 2,26 & 17,16 & 23,62 \\
\hline 2. & Bila 2 & 9,73 & 21,05 & 0,73 & 1,89 & 1,69 & 4,66 & 12,12 & 21,09 \\
\hline 3. & Bila 3 & 9,91 & 23,22 & 1,97 & 1,98 & 3,65 & 2,84 & 18,35 & 28,78 \\
\hline 4. & Taccipong & 7,74 & 29,32 & 3,08 & 3,87 & 2,73 & 0,53 & 13,07 & 23,27 \\
\hline 5. & L. Ajangale & 8,15 & 20,41 & 0,73 & 0,99 & 2,42 & 1,78 & 14,01 & 20,19 \\
\hline 6. & Teamusu 1 & 6,85 & 20,92 & 0,80 & 0,57 & 3,26 & 1,28 & 10,77 & 16,66 \\
\hline 7. & Teamusu 2 & 9,33 & 24,00 & 2,24 & 2,59 & 5,01 & 3,37 & 11,96 & 25,17 \\
\hline 8. & Seberang & 8,43 & 18,62 & 0,38 & 0,49 & 2,47 & 2,08 & 18,05 & 23,47 \\
\hline \multicolumn{2}{|c|}{ Rata-rata } & 8,36 & 22,51 & 1,25 & 1,65 & 3,14 & 2,63 & 15,00 & 23,70 \\
\hline
\end{tabular}

pohon lainnya karena sangat ditentukan oleh kondisi pohon yang akan ditebang dan tegakan yang ada di sekitarnya.

Faktor-faktor yang menjadi pertimbangan dalam penentuan arah rebah adalah kecondongan tajuk, kemiringan batang pohon, arah angin, tegakan bawah, dan faktor lainnya yang dapat menyebabkan kerusakan pohon dan tegakan di sekitar seperti tanaman kakao. Dalam kondisi penebangan yang berlawanan arah dengan pertimbangan tersebut seperti kecondongan tajuk, kemiringan batang, arah angin dan untuk menghindari kerusakan tanaman di sekitar, maka arah rebah diarahkan dengan memasang tali pada pohon yang ditebang kemudian ditarik dengan tali, bahkan sebagian tajuk terlebih dahulu di pangkas.

\section{Waktu pembuatan takik rebah}

Waktu pembuatan takik rebah adalah waktu yang digunakan untuk membuat takikan pada satu sisi batang dan membuangnya ke arah rebah yang dikehendaki. Rata-rata waktu yang digunakan untuk elemen kerja ini pada setiap lokasi berkisar antara 1,69-5,01 menit dengan rata-rata keseluruhan sebesar 3,14 menit. Waktu tersebut bervariasi antara satu pohon dengan pohon lainnya tergantung tingkat pengalaman operator dalam membaca karakteristik tegakan setelah menentukan arah rebah pohon yang akan ditebang dan tegakan yang ada di sekitarnya dan tinggi rendahnya mulut takik rebah yang dibuat.

Dengan demikian, pembuatan takik rebah harus tepat, yaitu perpotongan permukaan takik mendatar dan menyudut harus bertemu dalam satu garis agar fungsi takik rebah efektif karena bidang sejenis itu berfungsi sebagai engsel. Operator chainsaw telah membuat takik rebah sesuai dengan arah rebah yang telah direncanakan, namun ukuran mulut takik tersebut terlalu lebar. Takik rebah yang meleset dapat menyebabkan kerusakan pohon yang ditebang dan merusak tegakan di sekitarnya.

Takik rebah yang dipakai pada penebangan jati rakyat adalah yang konvensional. Takik rebah tersebut berdasarkan pengamatan lapangan memiliki banyak fungsi yaitu:

a) Menentukan arah rebahnya pohon atau pengarah rebahan pohon.

b) Mengendalikan batang yang sedang rebah tergelincir sesuai bentuk takik agar tidak meloncat.

c) Penuntun terciptanya suatu engsel setelah takik balas dibuat mendekati takik rebah.

d) Pencabut larik serat-serat kayu yang belum sepenuhnya terputus pada engsel tersebut.

\section{Waktu pembuatan takik balas}

Waktu pembuatan takik balas adalah waktu yang digunakan untuk memotong bagian penampang batang yang belum terpotong dari arah bertolak belakang arah takik rebah di atas garis pelurusan bidang horisontal (di atas alas takik rebah) sekitar 1-17 cm dengan rata-rata 7,38 $\mathrm{cm}$. Pada hutan alam selisih tinggi yang diperkenankan adalah $5-10 \mathrm{~cm}$, namun pada hutan tanaman 2-5 cm.

Takik balas tersebut tidak sejajar dengan alas takik rebah tetapi dibuat di atas alas takik rebah dengan selisih tinggi takik balas dari alas takik rebah melebihi dua $\mathrm{cm}$. Rata-rata waktu yang digunakan elemen kerja ini pada setiap lokasi berkisar antara 0,53-4,66 menit dengan rata-rata keseluruhan 2,63 menit.

Untuk mendapatkan volume kayu yang maksimal seharusnya operator chainsaw berjongkok, sehingga tinggi takik, tinggi tunggak sisa tebangan dan volume limbah lebih rendah. 


\section{Waktu pembagian batang}

Waktu pembagian batang adalah waktu yang digunakan untuk memotong batang menjadi sortimen dengan ukuran sesuai permintaan pasar. Rata-rata waktu yang digunakan untuk elemen kerja ini pada setiap lokasi berkisar antara 10,7718,35 menit dengan rata-rata keseluruhan sebesar 15,00 menit. Waktu yang digunakan tergantung jumlah potongan dan posisi batang yang akan dibagi. Posisi batang tersebut tidak terlepas dari hasil kerja waktu menebang. Semakin banyak jumlah potongan, maka waktu yang digunakan semakin lama.

Hasil pengamatan di lapangan menunjukkan bahwa kelancaran kegiatan pembagian batang sangat ditentukan oleh posisi kayu dan operator . Posisi kayu yang dimaksud adalah:

a) Posisi kayu yang berada pada permukaan yang rata, hampir tidak ditemukan kesulitan yang berarti.

b) Posisi kayu yang berada pada permukaan yang tidak rata, sehingga bisa terjadi kemungkinan posisi yang bervariasi dan akan berpengaruh terhadap proses pembagian batang. Variasi posisi tersebut adalah:

(1) Tekanan pada bagian atas

Tekanan pada bagian atas disebabkan kedua ujung kayu tertopang, sehingga berat kayu menimbulkan tekanan pada bagian atas dan pada bagian bawahnya meregang. Hal inilah sering menjadi permasalahan di lapangan yang menyebabkan bar chainsaw terjepit karena pemotongan dilakukan dari atas mendatar ke bawah. Jika pemotongan dilakukan sebaliknya yaitu dari bawah ke atas, maka kayu terputus sebelum selesai pemotongan yang menyebabkan bontos tercabik-cabik seluas permukaan yang terpotong.

(2) Tekanan pada bagian bawah

Posisi ini disebabkan kayu yang telah ditebang tertopang pada satu sisi saja atau sebagian batangnya menggantung. Pada posisi ini tekanan terjadi pada bagian bawah sedangkan yang meregang pada bagian atasnya. Jika pemotongan dilakukan dari bawah, maka bar terjepit sebelum pemotongan selesai. Sebaliknya dimulai dari atas, tetapi kayu terputus dan jatuh sebelum pemotongan selesai. Dengan demikian trimming harus dilakukan pada kedua bontos karena tercabik-cabik pada permukaan yang belum terpotong.

\section{Waktu total}

Waktu total atau penebangan adalah penjumlahan waktu yang digunakan pada setiap elemen kerja yaitu persiapan, penentuan arah rebah, pembuatan takik rebah dan takik balas serta pembagian batang. Rata-rata waktu yang digunakan pada setiap lokasi berkisar antara 16,66-28,78 menit dengan rata-rata keseluruhan sebesar 23,70 menit. Data waktu tebang tersebut diolah dan dianalisis dari 153 pohon yang ditebang pada sembilan lokasi penebangan dengan ratarata panjang kayu yang ditebang $8,36 \mathrm{~m}$, diameter rata-rata 22,51 dan volume rata-rata per pohon $0,355 \mathrm{~m}^{3}$

Waktu penebangan tersebut lebih tinggi dibandingkan dengan hasil penelitian Suhartana dan Yuniawati (2005) untuk kayu pinus (Pinus merkusii) yaitu waktu tebang efektif rata-rata per pohon adalah 13,73 menit dengan volume $2,91 \mathrm{~m}^{3}$. Waktu tebang efektif ini terdiri atas waktu merobohkan, waktu pembagian batang dan pengupasan kulit.

\section{Produktivitas kerja}

Produktivitas kerja kegiatan penebangan secara umum, lebih dipengaruhi faktor-faktor seperti jenis peralatan, intensitas penebangan dan sistem pengupahan yang digunakan. Semakin tinggi derajat mekanisasi peralatan yang digunakan maka semakin besar produktivitas kerja yang dihasilkan. Demikian juga jika dalam suatu areal terdapat banyak pohon yang akan ditebang maka produktivitas kerja akan semakin meningkat. Rekapitulasi produktivitas kerja penebangan disajikan pada Tabel 2.

Tabel 2 menunjukkan bahwa produktivitas rata-rata kegiatan penebangan setiap lokasi penebangan berkisar antara 0,59-1,03 $\mathrm{m}^{3} / \mathrm{jam}$ dengan rata-rata keseluruhan sebesar 0,854 $\mathrm{m}^{3} / \mathrm{jam}$. Sementara besarnya volume aktual ratarata per pohon setiap lokasi antara 0,235 - 0,527 $\mathrm{m}^{3}$ per pohon dengan rata-rata keseluruhan sebesar $0,355 \mathrm{~m}^{3}$. Waktu tebang per pohon berkisar 16,66-30,64 menit dengan rata-rata 23,70 menit/pohon. 
Tabel 2. Rekapitulation Felling Productivity on Community Teak Forest Bone Regency

\begin{tabular}{cccccrr}
\hline No. & Nama Lokasi/Desa & $\begin{array}{c}\text { Kelompok } \\
\text { Penebang }\end{array}$ & $\begin{array}{c}\text { Jumlah Pohon } \\
(\text { Batang })\end{array}$ & $\begin{array}{c}\text { Va } \\
\left(\mathrm{m}^{3}\right)\end{array}$ & $\begin{array}{c}\text { Wtp } \\
(\text { menit })\end{array}$ & Ptp (m3/jam) \\
\hline 1. & Bila 1 & I & 11 & 0,273 & 23,62 & 0,67 \\
2. & Bila 2 & II & 15 & 0,354 & 21,09 & 0,99 \\
3. & Bila 3 & III & 8 & 0,447 & 28,78 & 0,88 \\
4. & Taccipong & IV & 25 & 0,527 & 30,64 & 1,03 \\
5. & L. Ajangangale & V & 33 & 0,279 & 20,19 & 0,82 \\
6. & Teamusu 1 & VI & 30 & 0,243 & 16,66 & 0,84 \\
7. & Teamusu 2 & VII & 7 & 0,482 & 25,17 & 1,03 \\
8. & Seberang & VIII & 24 & 0,235 & 23,47 & 0,59 \\
\hline & Rata-rata & & 19 & 0,355 & 23,70 & 0,854 \\
\hline
\end{tabular}

Jam kerja rata-rata per hari sekitar delapan jam (09.00-17.00), namun waktu kerja yang digunakan secara efektif sekitar enam jam. Selisih waktu dua jam digunakan untuk istirahat makan siang, perpindahan lokasi tebang dan istirahat setiap selesai melakukan proses penebangan terhadap satu pohon. Dengan demikian produktivitas penebangan per hari hanya berkisar antara 3,51- 6,16 $\mathrm{m}^{3}$ dengan rata-rata $5,12 \mathrm{~m}^{3}$.

Sementara hasil penelitian produktivitas kerja penebangan untuk tiap-tiap jenis peralatan yang dilaporkan oleh Maryudi (2001,) bahwa pada hutan rakyat pola campuran yang didominasi tanaman sengon (Paraserianthes falcataria) adalah sebagai berikut :

1) Penggunaan kapak dengan produktivitas kerja $6,75 \mathrm{~m}^{3} /$ hari, anggota regu kerja tiga orang.

2) Penggunaan kapak dan gergaji tangan dengan produktivitas kerja $8,05 \mathrm{~m}^{3} / \mathrm{hari}$, anggota regu kerja tiga orang.

3) Penggunaan chainsaw dengan produktivitas kerja $14,14 \mathrm{~m}^{3} / \mathrm{hari}$, anggota regu kerja dua orang.

Dibandingkan dengan produktivitas kerja pada lokasi penelitian dengan menggunakan chainsaw berkisar antara 3,51- 6,16 $\mathrm{m}^{3} / \mathrm{hari}$ dengan rata-rata sekitar $5,12 \mathrm{~m}^{3} / \mathrm{hari}$, maka produktivitas kerja penebangan menurut Maryudi (2001), untuk tanaman sengon lebih tinggi yaitu sebesar 14,14 $\mathrm{m}^{3} /$ hari. Bahkan menggunakan kapak, kombinasi kapak dan gergaji tangan sekalipun produktivitasnya masih lebih tinggi. Perbedaan tersebut karena tanaman sengon termasuk kayu lunak yang berbanding terbalik dengan tanaman jati yang termasuk kayu kelas satu dan keras. Demikian pula hasil penelitian Suhartana dan Yuniawati (2005) untuk kayu pinus diperoleh produktivitas penebangan lebih tinggi yaitu berkisar antara 8,88-16,14 m3/jam dengan rata-rata 12,81 m/jam dan Suhartana, dkk. (2004) pada kayu Acacia mangium adalah 26,85 m³/jam.

Rendahnya produktivitas selama proses penebangan berlangsung, disebabkan oleh beberapa faktor antara lain aksesibilitas rendah, jumlah pohon yang ditebang pada setiap lokasi sedikit, pola penanaman campuran dan batas kebun membuat regu kerja membutuhkan waktu yang lama untuk mengarahkan arah rebah dan membagi batang agar dapat meminimalkan kerusakan tanaman yang tertimpa, sistem pengupahan terlalu mengejar target yang tinggi dengan sistem borongan.

Selain itu, pengalaman dan wawasan operator tentang optimalisasi pemanenan untuk memperoleh volume kayu yang optimal sangat menentukan. Pada Tabel 3 diuraikan deskripsi operator chainsaw pada setiap lokasi tebangan, sehingga dapat dianalisis dan dikaitkan dengan produktivitas kerja masing-masing karena semua lokasi memiliki karakteristik yang sama.

Karakteristik kondisi lapangan yang dimaksud yaitu topografi lapangan relatif datar (0-5\%), berada pada batas kebun atau tanaman campuran yang didominasi kakao, pemanenan dilakukan oleh pembeli, sistem upah borongan menurut jumlah potongan hasil pembagian batang, chainsaw tipe stihl 070, anggota regu kerja dua orang. Yang berbeda adalah pengalaman dan kemampuan setiap operator dalam menerjemahkan kondisi lapangan, sehingga produktivitas tersebut berbeda-beda. Deskripsi operator chainsaw menurut lokasi penebangan disajikan pada Tabel 3.

Pada Tabel 3 dapat dilihat bahwa operator chainsaw memiliki umur, pengalaman kerja dan umur chainsaw yang bervariasi. Variasi tersebut menghasilkan produktivitas kerja yang berbeda pula seperti diuraikan pada bagian sebelumnya. Umur operator chainsaw antara 30-49 tahun 
Tabel 3. Description Chainsaw Operators Based on Felling Location

\begin{tabular}{llccccc} 
No. & Nama Lokasi/Desa & $\begin{array}{c}\text { Kelompok } \\
\text { Penebang }\end{array}$ & $\begin{array}{c}\text { Jumlah } \\
\text { Pohon } \\
\text { (Batang) }\end{array}$ & $\begin{array}{c}\text { Umur } \\
\text { Chainsaw } \\
\text { (tahun) }\end{array}$ & $\begin{array}{c}\text { Pengalaman } \\
\text { kerja } \\
\text { (tahun) }\end{array}$ & $\begin{array}{c}\text { Umur } \\
\text { Operator } \\
\text { (tahun) }\end{array}$ \\
\hline 1. & Bila 1 & I & 25 & 3 & 7 & 35 \\
2. & Bila 2 & II & 15 & 2 & 6 & 39 \\
3. & Bila 3 & III & 7 & 7 & 5 & 42 \\
4. & Taccipong & IV & 11 & 3 & 4 & 30 \\
5. & L. Ajangangale & V & 33 & 5 & 8 & 42 \\
6. & Teamusu 1 & VI & 30 & 5 & 6 & 35 \\
7. & Teamusu 2 & VII & 7 & 7 & 10 & 49 \\
8. & Seberang & VIII & 24 & 4 & 4 & 38 \\
\hline \multicolumn{2}{r}{ Rata-rata } & & 19 & 4,5 & 6 & 38,75 \\
\hline
\end{tabular}

dengan rata-rata 38,75 tahun, pengalaman kerja sebagai operator antara 4-10 tahun dengan ratarata enam tahun. Sementara umur chainsaw yang digunakan berumur antara $2-7$ tahun dengan rata-rata 4,5 tahun.

Chainsaw yang telah berumur $>5$ tahun telah melewati umur ekonomis, namun secara teknis masih dapat digunakan karena telah dilakukan perbaikan dengan mengganti suku cadang yang telah aus.

\section{KESIMPULAN}

Berdasarkan analisis terhadap hasil penelitian, maka dapat ditarik kesimpulan bahwa produktivitas penebangan pada hutan jati rakyat di Kabupaten Bone adalah sebesar 5,12 $\mathrm{m}^{3}$ /hari Rendahnya produktivitas selama proses penebangan berlangsung, disebabkan oleh beberapa faktor antara lain aksesibilitas rendah, jumlah pohon yang ditebang pada setiap lokasi sedikit, pola penanaman campuran dan batas kebun membuat regu kerja membutuhkan waktu yang lama untuk mengarahkan arah rebah dan membagi batang agar dapat meminimalkan kerusakan tanaman yang tertimpa, sistem pengupahan terlalu mengejar target yang tinggi dengan sistem borongan.

Diterima: 11 November 2008

Andi Mujetahid

Lab. Pemanenan dan Pembukaan Wilayah Hutan Jurusan Kehutanan, Universitas Hasanuddin Kampus Tamalanrea, Jl. Perintis Kemerdekaan Km. 10, Makassar 90245 Telp./Fax. 0411-585917. Indonesia

\section{DAFTAR PUSTAKA}

Elias. 1987. Analisa Biaya Eksploitasi Hutan. Bogor: Fakultas Kehutanan Institut Pertanian Bogor.

Endom, W. 1996. Perbaikan Teknik Penebangan untuk Minimasi Limbah Pembalakan dengan Cara Penurunan Tinggi Mulut Takik Rebah. Buletin Penelitian Hasil Hutan. 14 (7): 253-263.

Maryudi, A. 2001. Analisis Produktivitas Kerja dan Biaya Pemanenan Hasil Hutan di Hutan Rakyat. Jurnal Hutan Rakyat: 4 (1): 35-53.

Suhartana, S. dan Yuniawati. (2005). Meningkatkan Produktivitas Kayu Pinus Melalui Penebangan Serendah Mungkin: Studi Kasus di KPH Sumedang, Perum Perhutani Unit III Jawa Barat. Info Hasil Hutan.11(2): 8796.

Suhartana, S., M. Sinaga, dan I. Sumantri. (2004). Peningkatan Produktivitas dan Efisiensi Penebangan Kayu Mangium di Satu perusahaan Hutan Tanaman di Propinsi Jambi. Jurnal Penelitian Hasil Hutan. 22(3): 175-182. 